\title{
A hard act to follow: the contribution of Tim New
}

\author{
T. G. Shreeve
}

Published online: 12 January 2010

(C) Springer Science+Business Media B.V. 2010

For any incoming editor there are two immediate challenges. The first is to ensure that the journal continues to increase in impact in an increasingly competitive and changing journal market. This can only be done by ensuring that this journal becomes, or remains, the first choice outlet for dissemination of important contributions in the field of insect conservation. A healthy journal has to have contributions from key scientists with international reputations, yet at the same time encourage and facilitate early career scientists to publish in it too. The second challenge is to reflect on the steer and direction that the previous editor has given to the journal and to ensure that the successes of the previous editor serve as a building block for the future.

The first edition of the Journal of Insect Conservation was in 1997, and Tim New took over the role of editor-inchief in 2003, initially in a declared caretaker role. 7 years later he has handed over the reigns to myself and it is very clear that his is a hard act to follow. During his overseeing of the journal it gained its first ISI impact factor of 0.69 for 2007 (41st of 73 entomology journals), which has now increased to 1.83 (10th of 72). This is clear evidence that the journal's profile as a mainstream publication for communicating the science, ideas and issues of insect conservation has increased dramatically. The ranking also puts the journal ahead of many much longer established journals. This increase in impact can be related directly to Tim New's stewardship and his activities for the journal deserve clear recognition.

T. G. Shreeve $(\bowtie)$

School of Life Sciences, Oxford Brookes University,

Headington, Oxford OX3 OBP, UK

e-mail: tgshreeve@brookes.ac.uk
Tim New has more than 30 years experience of the science and application of invertebrate conservation, and is a recognised international authority, not just on the science, but on the issues surrounding how to make conservation work. $\mathrm{He}$ has an acute recognition that conservation requires more than science. His commitment to conservation clearly recognises that it requires engagement and dialogue between scientists, politicians and practitioners to maximise the chance that conservation science becomes a success by reversing the tide of loss and destruction. This recognition has placed Tim at the forefront of those who recognise that novel approaches are sometimes needed and that conservationists need to be aware of the limitations of their science and the implications of what they advocate. At the heart of this is obviously the development of an adequate evidence base on which to make decisions and this is where Tim's role as a journal editor has been critical.

As the editor-in-chief, Tim New adopted a perceptive and dynamic approach to his role. He has encouraged debate and differences of opinion, thereby strengthening the importance of the journal. One of Tim's strengths has been to use the review process positively. Reviewers can occasionally differ in their opinions on particular submissions, potentially making the editorial decision making process a difficult task Tim used the review process to reach conclusions as to how manuscripts could be progressed, taking the time and paying the courtesy to submitting authors to provide full explanations for decisions and where necessary, making invaluable suggestions. Under his control, the perception of submitting authors will therefore have been one of encouragement rather than one of a discouraging uphill battle to get work published, which can sometimes be the case with the peer review process. This approach of encouragement has clearly worked, as evidenced by the increasing ISI ranking. 
Over his time, the format of the journal has changed. Whilst Original Papers remain central to the journal, as do Book Reviews, Tim introduced Short Communications, Reviews and Point-in-View sections, allowing authors a flexible journal for communicating not just the evidence base for conservation science but opinion and novel ideas as well. This has certainly helped to increase interest in the journal and has made it a dynamic forum for communication. At the same time Tim produced regular editorials (one per issue), which have always been incisive, and sometimes controversial. Questioning perceived wisdom, the supporting evidence and the consequences of implementing policy recommendations, together with examining issues around transferring practices and policies from one region to another provide the key themes to many of these editorials. They give an insight into why Tim extended the types of papers in the journal; science needs to be applied but there are issues about how this is done and what the evidence base for practices are. Whilst some of these originate from an Australian perspective, the issues they have covered are global and have been well worth reading. Tim was particularly keen to see the journal publish Special Issues, allowing for individuals or groups to invite authors to submit relevant papers around coherent themes. These Special Issues now run at about one per year. As with his reorganising of the scope of the content, these Special Issues have helped raise interest in the journal, enabling it become a vehicle to address specific issues in a focused manner.

During his stewardship the number of issues per year and the total number of papers published per year has also grown, currently there are now 6 issues per year as opposed to 4 when Tim took over and the number of papers produced has increased equivalently. On-line first publications point to the health of the journal as well. Whilst the overall objectives and purpose of the journal have not changed, the scope, by way of taxonomic groups and geographic coverage has increased, indicating that under Tim's safe editorial hands a widening scientific community has come to recognise the journal's growing importance.

Tim New has been continuously encouraging to authors and, in his capacities as editor and as an independent scientist frequently attends meetings and symposia, promoting the journal where and when appropriate. His enthusiasm and hard work has made the journal a mainstream outlet for conservation science, thereby doing insect conservation an enormous service. Although, in his own words, when talking about invertebrate conservationists "many people do still indeed regard us as cranks", his activities have done much to dispel this myth and raise the credibility of insect conservationists as mainstream contributors to conservation science and practice.

I only hope, as I take over the role of editor-in chief, that I can live up to Tim New's boundless energy and enthusiasm, and undertake the role of editor-in-chief with equal grace and humour. I hope that Tim looks on the journal with pride, and continues to submit papers. The current standing of the journal owes so much to his hard work. His task, in getting the journal established and well regarded, was much harder than the one I have, which is to build on the secure foundations he has laid.

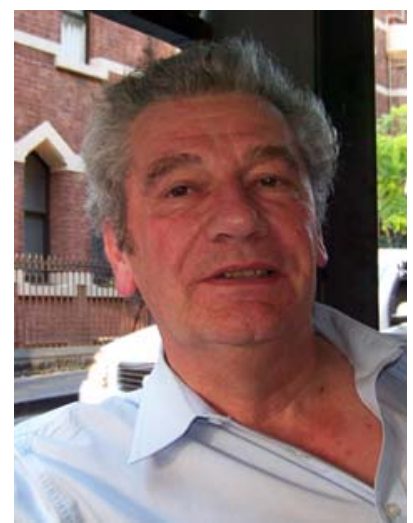

Tim New, Editor-in-chief, 2003-2009 